\title{
Advocating for a Collaborative Research Approach on Transgenerational Transmission of Trauma
}

\author{
Suria Afifah Ridhuan ${ }^{1}$ - Anna Caltabiano ${ }^{1}$ - Harry Gillis ${ }^{1}$ - Ali Giritlioğlu ${ }^{1}$ - Anna Graff ${ }^{1}$ - L. E. Hampikian ${ }^{1}$. \\ Ariadin K. Jones $^{1} \cdot$ Philip Luetgerath $^{1} \cdot$ Aidan Pierce $^{1}$ (D) $\cdot$ Emma Pomeroy $^{1} \cdot$ Rihlat Said-Mohamed $^{1}$
}

Accepted: 24 May 2021 / Published online: 3 June 2021

(C) The Author(s), under exclusive licence to Springer Nature Switzerland AG 2021

\begin{abstract}
Since Myers (1915) coined the term 'shell shock' to define the prolonged suffering of soldiers returning from the Great War, the psychological and physical result of distressing experiences, known as trauma, has been of academic interest. Transgenerational transmission of trauma effects has been recorded, demonstrating that on some level, the exposure to trauma of one generation can impact individuals of a subsequent generation (Yehuda \& Lehrner, 2018). Observational studies on children of holocaust survivors formed the basis of this trajectory of research (Rakoff, 1966), and eventually this phenomenon became referred to as the transgenerational transmission of trauma (TTT). Since then, TTT has been observed in several contexts, including within families who have experienced high rates historical trauma (O'Neill et al., 2016), within regions high-frequencies of historical war and terrorism (Yehuda \& Lehrner, 2018) and those who have undergone famine (Ahmed, 2010). This report aims to outline several pathways (biological, psychological, and sociological) by which trauma may be transmitted across generations. Moreover, it discusses several methods of trauma assessment and the related challenges and benefits. Lastly, this report advocates a biopsychosocial approach - an interdisciplinary model using the interplay of biological, psychological, and socialenvironmental factors - to research TTT. By promoting the benefits of such an interdisciplinary approach we attempt to break up silos between disciplines and encourage collaboration between academics from various backgrounds researching this topic to better serve individuals impacted by TTT.
\end{abstract}

Keywords Trauma $\cdot$ Biopsychosocial $\cdot$ Collaboration

\section{Report}

The psychological and physical result of distressing experiences is known to affect more than just the primary experiencers of such trauma and can span over several generations (Hanover, 1981). Transgenerational transmission of trauma (TTT) is fundamentally defined as the transmission of the effect of an experience of trauma from an individual or group of individuals in one generation to an individual(s) in later generations (Yehuda \& Lehrner, 2018; O'Neill et al., 2018). TTT encompasses both more direct intergenerational transmission (from F0 to F1), as well as generation-skipping

Aidan Pierce

app48@cantab.ac.uk

1 Department of Archaeology, University of Cambridge, Cambridge, UK transgenerational transmission (from F0 to $\mathrm{F} 3$ or F4, etc.) (Yehuda \& Lehrner, 2018). Thus far, the transmission of secondary traumatic stress between individuals affected by primary trauma and their descendents has proven to be difficult for researchers to model. This has been attributed to the various confounding socio-cultural factors that affect a child's development (Bakó \& Zana, 2018; Burchert et al., 2017; Fossion et al., 2015). Thus, as the mechanisms by which trauma is transmitted between generations spans biological, psychological, and sociological factors, the study of TTT requires elements from each of these fields in order to facilitate a holistic understanding.

Several methods of assessment can be utilized to assess the severity of secondary trauma, such as psychological questionnaires. However, this traditional method of evaluation is vulnerable to a series of biases. Examples may include suggestive-questioning, a differing understanding of the answering scales, and cultural influences (Choi \& Pak, 2005; Smit et al., 1997). Therefore, in regard to the latter, they must be 
employed with great caution when applied to a range of cultural contexts (Choi \& Pak, 2005). Outside of such biases, individuals can also demonstrate a tendency to conceal the manifestations of their trauma when confronted for research purposes (Burchert et al., 2017; Pearrow \& Cosgrove, 2009). This leads to a variety of complications when research in this field relies so heavily on self-administered questionnaires and serves as an example as to why diversifying current research methodologies is necessary (Fossion et al., 2015).

In contrast, as questionnaires can entail certain methodological problems, a series of studies has tried to measure trauma using manifest hormonal levels as dependent variables. Specifically, the glucocorticoid (GC) cortisol has been used as a proximate variable, as it is involved in physiological stress response, blood glucose regulation, immune function regulation and behaviour (Sapolsky et al., 2000; Taves et al., 2011). To assess the association between stress and cortisol a series of measurements have been employed including cortisol baseline level (Vermeer, \& van IJzendoorn, M. H., 2006; Yehuda et al., 2007), cortisol secretion reactivity (Edelstein et al., 2010; Jansen et al., 2010), cortisol awakening response (Chida \& Steptoe, 2009) or cortisol level recovery after exposure (Roy et al., 1998).

Despite being a latecomer to the study of TTT, the use of genome-wide association studies and molecular genetics techniques have revealed a hidden channel for trauma to transmit across generations. Substantial experimental work on male rodents and observational studies in humans support the idea that paternal exposure to trauma, prior to conception, can influence offspring phenotypes through epigenetic modifications of sperm. For example, Rodgers et al. (2013) report dysregulated hypothalamic-pituitary-adrenal (HPA) stress axis responsiveness in the offspring of male mice exposed to chronic stress for six weeks prior to breeding. Analysis of potential mechanisms revealed that the stressexposed group exhibited altered sperm microRNA content, however, wider research on murine models has also implicated the contribution of other epigenetic mechanisms including DNA methylation, histone modifications and other noncoding RNAs (Szyf, 2015; Yehuda \& Lehrner, 2018). One recent study revealed that early-life exposure to stressors in human males, as assessed by the Adverse Childhood Experience (ACE) questionnaire, was inversely associated with microRNA expression from the miR-449/34 family (Dickson et al., 2018). Somewhat remarkably, this pattern was mirrored in a sample of male mice also exposed to early-life stressors (Dickson et al., 2018). Whilst it is highly likely that similar effects occur in female gametes, potential confounders such as modified fetoplacental interactions and maternal caregiving behaviour make it more difficult to disentangle the effects of these alternative mechanisms (Yehuda \& Lehrner, 2018).

Genes implicated within the stress-related epigenetic methylation are known to be involved with a dysfunctional GC response, which are key hormones in signalling across the hypothalamic-pituitary-adrenal (HPA) axis. For example, $N R 3 C 1$, a GC receptor gene, has been reported to be methylated following extreme prenatal maternal stress in the Democratic Republic of Congo, a region plagued by ongoing war and extreme violence to women, eliciting its effect across generational barriers through its association with offspring birth weight (Mulligan et al., 2012). Moreover, one family of genes associated with transgenerational trauma is the FK506-binding protein (FKBP) family. Members of this family are heat shock proteins involved with the folding of novel proteins in the cytoplasm, with FK506-binding protein 5 gene (FKBP5) having a key regulatory role within stress hormone systems. Methylation of FKBP5 has been widely associated with TTT (Binder et al., 2008; Yehuda et al., 2016), with some studies supporting the hypothesis that trauma-dependent methylation of FKBP5 increases the likelihood of developing psychiatric disorders, particularly depression and PostTraumatic Stress Disorder (PTSD) (Klengel et al., 2013). The specific allele implicated with this effect is associated with the GC response element of the FKBP5 protein (Klengel et al., 2013). These associated genes (the FKBP family and $N R 3 C 1$ ) and their respective proteins show a GCdependent response which affects infant phenotypic expression of psychiatric disorders later in life (Stenz et al., 2018).

In addition to the genetic mechanisms of transmission, there are various pathways in-utero and ex-utero by which traumatic experiences may be transmitted across generations. Maternal prenatal stress and PTSD can result in impaired uterine blood flow, low birth weight, and preterm birth (reviewed in Bowers \& Yehuda, 2016). These factors are in turn associated with adult hypertension, insulin resistance, Type 2 diabetes, and cardiovascular disease in offspring (Barker, 1998). This supports the developmental origins of health and disease hypothesis (Gluckman \& Hanson, 2006), which posits that in utero and early life exposure to environmental factors during critical periods of developmental plasticity, including parental stress and PTSD, predispose the fetus to later disease across the life course. Evidence for effects of parental PTSD on fetal development and neonatal disease has been found throughout the world and throughout difficult times in history: long-term effects have for instance been observed in adult offspring of Holocaust survivors, who are at significantly greater risk for PTSD, depression, and anxiety disorders (Yehuda et al., 2008). Offspring of women exposed to famine and its physiological and psychological consequences in utero were found to be at greater risk of poor health later in life than the offspring of unexposed women and at risk of increased BMI in adulthood following paternal exposure (e.g. in the Dutch Hunger Winter: Painter et al., 2008; Veenendaal et al., 2013). Similar effects were found following the famine in The Gambia (Eriksen et al., 2017). The effects of parental stress-exposures on offspring development appear to be 
uneven across pregnancy trimesters (e.g. following the 9/11 terror attacks: Yehuda et al., 2005), suggesting that stressinduced influences on fetal development partly depend on fetal age and pregnancy stage.

Specific cultural environments may intensify circumstances under which trauma is transmitted transgenerationally. For example, researchers in Cambodia conducted a survey on the offspring of Khmer Rouge survivors and noticed a genderbias, with female offspring presenting significantly higher in the severity of symptoms relating to trauma exposure (Burchert et al., 2017). This bias was later linked to young women spending prolonged amounts of time with their parents, particularly their mothers, in comparison to their male counterparts (Burchert et al., 2017). Overall, two mechanisms of psychological transmission seem to span the current literature: over-exposure (caring for, helping, or wanting to aid a traumatized person) and concealment (unavailability, detachment, and disinterest) (Burchert et al., 2017; Figley, 1993; Pearrow \& Cosgrove, 2009). Over-exposure to an individual who has suffered a traumatic experience is aligned with a dose-response effect (Dekel \& Goldblatt, 2008). For example, when veterans with PTSD convey their trauma to loved ones the maladaptive experience can be transmitted through emotional contagion (Figley, 1999). Naturally, this is not isolated to their offspring and can affect filial and marital relationships as well. A study conducted by Bachem et al. in 2018 highlighted the importance of marital partners who have suffered secondary traumatic stress, particularly mothers, and TTT. In this aspect, family dynamics, including the quality of paternal care, are a critical factor despite their variable nature.

Whilst the examples previously listed draw from individual disciplines, modern traumatic events enable a collaborative approach to be taken drawing research design from biological, psychological, and sociological aspects. For example, the global COVID-19 pandemic may have varying influences on an individual's mental health depending on the adverse change seen dependent on national and international procedures, how these were communicated, and the long-term economic prospects as a consequence of these procedures. In addition to this, the refugee crisis or wars around the world such as in Syria or Yemen provide cases where the implications of severe trauma across several generations can be studied using this biopsychosocial approach.

As outlined, studying TTT requires complex scientific designs. Yet, in order to increase comparability between studies and advance research into TTT, methodological consistency is clearly needed. This could be achieved by adopting a unified biopsychosocial framework: to facilitate integrated individual-centred treatment and ensure a more complete academic understanding, collaboration between diverse academic fields, including psychology, biology, medicine, sociology and history is crucial. Such an approach resembles that taken by the Research Domain Criteria (Insel et al., 2010) in the field of psychopathology and may result in comparable metrics or assessments for the extent of primary and secondary trauma experienced transgenerationally.

\section{Conclusions}

In this report we wanted to highlight the various pathways by which trauma may be transmitted across generations. The fact that TTT touches various research domains makes it a complex and challenging scientific field in which various possible confounders with complementary or alternative hypotheses from other disciplines need to be respected in a given research design. Our paper promotes an interdisciplinary biopsychosocial approach to understanding these intergenerational mechanisms and effects of trauma to help provide context for how to address and understand complex social problems today. We hope that using such an approach will aid the decisions of academics, clinicians and policymakers.

Authors Contribution No first author was declared. The rank order of authors was established by alphabetical order. Dr. Emma Pomeroy and Dr. Rihlat Said-Mohamed share senior authorship.

\section{Declarations}

Ethics Approval Due to the nature of this report, the receipt of ethical approval was not necessary.

Conflict of Interest The authors have no conflicts of interest to declare that are relevant to the content of this article.

\section{References}

Ahmed, F. (2010). Epigenetics: Tales of adversity. Nature., 468, S20. https://doi.org/10.1038/468S20a.

Bachem, R., Levin, Y., Zhou, X., Zerach, G., \& Solomon, Z. (2018). The role of parental posttraumatic stress, marital adjustment, and dyadic self-disclosure in intergenerational transmission of trauma: A family system approach. Journal of Marital and Family Therapy., 44, 543555. https://doi.org/10.1111/jmft.12266.

Bakó, T., \& Zana, K. (2018). The vehicle of transgenerational trauma: The transgenerational atmosphere. American Imago., 75, 271-285. https://doi.org/10.1353/aim.2018.0013.

Barker, D. J. P. (1998) 'In utero programming of chronic disease', Clinical Science. https://doi.org/10.1042/cs0950115.

Binder, E. B., Bradley, R. G., Liu, W., Epstein, M. P., Deveau, T. C., Mercer, K. B., Tang, Y., Gillespie, C. F., Heim, C. M., Nemeroff, C. B., Schwartz, A. C., Cubells, J. F., \& Ressler, K. J. (2008). Association of FKBP5 polymorphisms and childhood abuse with risk of posttraumatic stress disorder symptoms in adults. JAMA Journal of the American Medical Association., 299, 1291-1305. https://doi.org/10.1001/jama.299.11.1291. 
Bowers, M. E., \& Yehuda, R. (2016). Intergenerational transmission of stress in humans. Neuropsychopharmacology., 41, 232-244. https:// doi.org/10.1038/npp.2015.247.

Burchert, S., Stammel, N., \& Knaevelsrud, C. (2017). Transgenerational trauma in a post-conflict setting: Effects on offspring PTSS/PTSD and offspring vulnerability in Cambodian families. Psychiatry Research, 254, 151-157. https://doi.org/10.1016/j.psychres.2017. 04.033 .

Chida, Y., \& Steptoe, A. (2009). Cortisol awakening response and psychosocial factors: A systematic review and meta-analysis. Biological Psychology, 80, 265-278. https://doi.org/10.1016/j. biopsycho.2008.10.004.

Choi, B. C. and Pak, A.W. (2005). Peer reviewed: a catalog of biases in questionnaires. Preventing chronic disease, 2(1).

Dekel, R., \& Goldblatt, H. (2008). Is there intergenerational transmission of trauma? The case of combat veterans Children. American Journal of Orthopsychiatry., 78, 281-289. https://doi.org/10.1037/ a0013955.

Dickson, D. A., Paulus, J. K., Mensah, V., Lem, J., Saavedra-Rodriguez, L., Gentry, A., Pagidas, K., \& Feig, L. A. (2018). Reduced levels of miRNAs 449 and 34 in sperm of mice and men exposed to early life stress. Translational Psychiatry, 8, 101. https://doi.org/10.1038/ s41398-018-0146-2.

Edelstein, R. S., Yim, I. S., \& Quas, J. A. (2010). Narcissism predicts heightened cortisol reactivity to a psychosocial stressor in men. Journal of Research in Personality., 44, 565-572. https://doi.org/ 10.1016/j.jrp.2010.06.008.

Eriksen, K. G., Radford, E. J., Silver, M. J., Fulford, A. J. C., Wegmüller, R., \& Prentice, A. M. (2017). Influence of intergenerational in utero parental energy and nutrient restriction on offspring growth in rural Gambia. FASEB Journal., 31, 4928-4934. https://doi.org/10.1096/ fj.201700017R.

Figley, C. R. (1993). Coping with stressors on the home front. Journal of Social Issues., 49, 51-71. https://doi.org/10.1111/j.1540-4560. 1993.tb01181.x.

Figley, C. R. (1999). Compassion fatigue: Toward a new understanding of the costs of caring. Secondary Traumatic Stress. Self-Care Issues for Clinicians, Researchers and Educators.

Fossion, P., Leys, C., Vandeleur, C., Kempenaers, C., Braun, S., Verbanck, P., \& Linkowski, P. (2015). Transgenerational transmission of trauma in families of Holocaust survivors: The consequences of extreme family functioning on resilience, sense of coherence, anxiety and depression. Journal of Affective Disorders., 171, 4853. https://doi.org/10.1016/j.jad.2014.08.054.

Gluckman, P., \& Hanson, M. (2006). Developmental origins of health and disease. Developmental Origins of Health and Disease. https:// doi.org/10.1017/CBO9780511544699.

Hanover, L. A. (1981). Parent-child relationships in children of survivors of the Nazi holocaust. ProQuest Dissertations and Theses.

Insel, T., Cuthbert, B., Garvey, M., Heinssen, R., Pine, D. S., Quinn, K., Sanislow, C., \& Wang, P. (2010). Research Domain Criteria (RDoC): Toward a new classification framework for research on mental disorders. American Journal of Psychiatry., 167, 748-751. https://doi.org/10.1176/appi.ajp.2010.09091379.

Jansen, J., Beijers, R., Riksen-Walraven, M., \& de Weerth, C. (2010). Cortisol reactivity in young infants. Psychoneuroendocrinology., 35, 329-338. https://doi.org/10.1016/j.psyneuen.2009.07.008.

Klengel, T., Mehta, D., Anacker, C., Rex-Haffner, M., Pruessner, J. C., Pariante, C. M., Pace, T. W. W., Mercer, K. B., Mayberg, H. S., Bradley, B., Nemeroff, C. B., Holsboer, F., Heim, C. M., Ressler, K. J., Rein, T., \& Binder, E. B. (2013). Allele-specific FKBP5 DNA demethylation mediates gene-childhood trauma interactions. Nature Neuroscience., 16, 33-41. https://doi.org/10.1038/nn.3275.

Mulligan, C. J., et al. (2012). Methylation changes at NR3C1 in newborns associate with maternal prenatal stress exposure and newborn birth weight. Epigenetics., 7, 853-857. https://doi.org/10.4161/epi. 21180 .

Myers, C. S. (1915). A contribution to the study of shell shock. Being an account of three cases of loss of memory, vision, smell, and taste, admitted into the duchess of Westminster's War Hospital, Le Touquet. The Lancet., 185, 316-320. https://doi.org/10.1016/ S0140-6736(00)52916-X.

O’Neill, L., Fraser, T., Kitchenham, A., \& McDonald, V. (2018). Hidden burdens: A review of intergenerational, historical and complex trauma, implications for indigenous families. Journal of Child and Adolescent Trauma., 11, 173-186. https://doi.org/10.1007/s40653016-0117-9.

Painter, R. C., Osmond, C., Gluckman, P., Hanson, M., Phillips, D. I. W., \& Roseboom, T. J. (2008). Transgenerational effects of prenatal exposure to the Dutch famine on neonatal adiposity and health in later life. BJOG: An International Journal of Obstetrics and Gynaecology., 115, 1243-1249. https://doi.org/10.1111/j.14710528.2008.01822.x.

Pearrow, M., \& Cosgrove, L. (2009). The aftermath of combat-related PTSD: Toward an understanding of transgenerational trauma. Communication Disorders Quarterly., 30, 77-82. https://doi.org/ $10.1177 / 1525740108328227$

Rakoff, V. (1966). A long term effect of the concentration camp experience. Viewpoints.

Rodgers, A. B., Morgan, C. P., Bronson, S. L., Revello, S., \& Bale, T. L. (2013). Paternal stress exposure alters sperm MicroRNA content and reprograms offspring HPA stress axis regulation. Journal of Neuroscience., 33, 9003-9012. https://doi.org/10.1523/ JNEUROSCI.0914-13.2013.

Roy, M. P., Steptoe, A., \& Kirschbaum, C. (1998). Life events and social support as moderators of individual differences in cardiovascular and cortisol reactivity. Journal of Personality and Social Psychology., 75, 1273-1281. https://doi.org/10.1037/0022-3514. 75.5.1273.

Sapolsky, R. M., Romero, L. M., \& Munck, A. U. (2000). How do glucocorticoids influence stress responses? Integrating permissive, suppressive, stimulatory, and preparative actions. Endocrine Reviews., 21, 55-89. https://doi.org/10.1210/er.21.1.55.

Smit, J. H. and van der Zouwen, J. (1997). Suggestive interviewer behaviour in surveys: An experimental study. Journal of Official Statistics, 13(1), p.19.

Stenz, L., Schechter, D. S., Serpa, S. R., \& Paoloni-Giacobino, A. (2018). Intergenerational transmission of DNA methylation signatures associated with early life stress. Current Genomics, 19, 665-675. https:// doi.org/10.2174/1389202919666171229145656.

Szyf, M. (2015). Nongenetic inheritance and transgenerational epigenetics. Trends in Molecular Medicine., 21, 134-144. https://doi. org/10.1016/j.molmed.2014.12.004.

Taves, M. D., Gomez-Sanchez, C. E., \& Soma, K. K. (2011). Extraadrenal glucocorticoids and mineralocorticoids: Evidence for local synthesis, regulation, and function. American Journal of Physiology - Endocrinology and Metabolism., 301, E11-E24. https://doi.org/ 10.1152/ajpendo.00100.2011

Veenendaal, M. V. E., Painter, R. C., de Rooij, S. R., Bossuyt, P. M. M., van der Post, J., Gluckman, P. D., Hanson, M. A., \& Roseboom, T. J. (2013). Transgenerational effects of prenatal exposure to the 1944-45 Dutch famine. BJOG: An International Journal of Obstetrics and Gynaecology., 120, 548-554. https://doi.org/10. 1111/1471-0528.12136.

Vermeer, H. J., \& van IJzendoorn, M. H. (2006). Children's elevated cortisol levels at daycare: A review and meta-analysis. Early Childhood Research Quarterly., 21, 390-401. https://doi.org/10. 1016/j.ecresq.2006.07.004.

Yehuda, R., \& Lehrner, A. (2018). Intergenerational transmission of trauma effects: Putative role of epigenetic mechanisms. World Psychiatry, 17, 243-257. https://doi.org/10.1002/wps.20568. 
Yehuda, R., Engel, S. M., Brand, S. R., Seckl, J., Marcus, S. M., \& Berkowitz, G. S. (2005). Transgenerational effects of posttraumatic stress disorder in babies of mothers exposed to the world trade center attacks during pregnancy. Journal of Clinical Endocrinology and Metabolism., 90, 4115-4118. https://doi.org/10.1210/jc.2005-0550.

Yehuda, R., Teicher, M. H., Seckl, J. R., Grossman, R. A., Morris, A., \& Bierer, L. M. (2007). Parental posttraumatic stress disorder as a vulnerability factor for low cortisol trait in offspring of holocaust survivors. Archives of General Psychiatry., 64, 1040-1048. https:// doi.org/10.1001/archpsyc.64.9.1040.

Yehuda, R., Bell, A., Bierer, L. M., \& Schmeidler, J. (2008). Maternal, not paternal, PTSD is related to increased risk for PTSD in offspring of Holocaust survivors. Journal of Psychiatric Research, 42, 1104 1111. https://doi.org/10.1016/j.jpsychires.2008.01.002.

Yehuda, R., Daskalakis, N. P., Bierer, L. M., Bader, H. N., Klengel, T., Holsboer, F., \& Binder, E. B. (2016). Holocaust exposure induced intergenerational effects on FKBP5 methylation. Biological Psychiatry, 80, 372-380. https://doi.org/10.1016/j.biopsych.2015. 08.005 .

Publisher's Note Springer Nature remains neutral with regard to jurisdictional claims in published maps and institutional affiliations. 